Slavica

bruxellensia

\section{Slavica bruxellensia}

Revue polyphonique de littérature, culture et histoire

slaves

$1 \mid 2008$

Théâtre

\title{
Les Tchèques et les Belges : une histoire en miroir (sous la direction de Sarah Flock, Jiří Kocian, Jan Rubeš et Oldřich Tůma)
}

Nicolas Litvine

\section{CpenEdition}

Édition électronique

URL : http://journals.openedition.org/slavica/251

DOI : 10.4000/slavica.251

ISSN : 2034-6395

Éditeur

Université libre de Bruxelles - ULB

Édition imprimée

Pagination : 72

ISSN : 2031-7654

Référence électronique

Nicolas Litvine, «Les Tchèques et les Belges : une histoire en miroir (sous la direction de Sarah Flock, Jiř́ Kocian, Jan Rubeš et Oldřich Tůma) », Slavica bruxellensia [En ligne], 1 | 2008, mis en ligne le 15 octobre 2008, consulté le 22 septembre 2020. URL : http://journals.openedition.org/slavica/251 ; DOI : https://doi.org/10.4000/slavica.251

Ce document a été généré automatiquement le 22 septembre 2020.

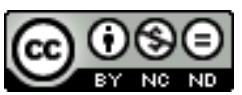

Les contenus de Slavica bruxellensia sont mis à disposition selon les termes de la Licence Creative Commons Attribution - Pas d'Utilisation Commerciale - Pas de Modification 3.0 France. 


\title{
Les Tchèques et les Belges : une histoire en miroir (sous la direction de Sarah Flock, Jiř́i Kocian, Jan Rubeš et Oldřich Tůma)
}

\author{
Nicolas Litvine
}

\section{RÉFÉRENCE}

Les Tchèques et les Belges : une histoire en miroir(sous la direction de Sarah Flock, Jiří Kocian, Jan Rubeš et Oldřich Tủma), Bruxelles, Institut de l'Histoire contemporaine de l'Académie des Sciences de la République tchèque, Centre d'Études tchèques de l'Université libre de Bruxelles, 2008, 166 p.

1 La séparation géographique et plus de quarante ans de Guerre froide ont contribué à mettre en évidence ce qui sépare les pays d'Europe de l'ouest de ceux d'Europe centrale en général, les Belges des Tchèques en particulier. Pourtant, ces peuples partagent de nombreux points communs, de la position géographique d'un petit état entouré de grands voisins à l'histoire commune sous la domination des Habsbourg, en passant par l'expérience commune - passée pour les Tchèques, très actuelle pour les Belges - d'un état fédéral biculturel.

2 Voici donc un recueil de 14 articles, réalisé conjointement par des universitaires tchèques et belges, qui vise à rééquilibrer le regard que se portent réciproquement ces deux peuples. On y trouvera l'évocation tant des expériences communes (comme celle du passé habsbourgeois ou des contacts dans le domaine de l'art) que du passé national propre (de la mythologie nationale belge du $\mathrm{XIX}^{\mathrm{e}}$ siècle à la déstalinisation en Tchécoslovaquie), sans oublier les moments d'incompréhension ou de malentendu (notamment les relations entre surréalistes des deux pays). Sans prétendre à l'exhaustivité, en 160 pages, les auteurs nous offrent une série de regards diversifiés sur 
le passé proche et lointain, dans l'espoir, exprimé en introduction par Jan Rubeš et Oldřich Tůma, "qu'au-delà du passé habsbourgeois, nous [ayons] aussi un avenir commun ».

INDEX

Mots-clés : histoire de la Belgique, histoire tchèque

Index géographique : Belgique, République tchèque, Tchécoslovaquie

\section{AUTEURS}

NICOLAS LITVINE

Étudiant à l'Université Libre de Bruxelles en Langues et Littératures modernes, orientation slaves 